\title{
EFFECTS OF BARBITURATE ANESTHESIA (EVIPAL AND PENTOTHAL SODIUM) UPON THE INTEGRATION OF RESPIRATORY CONTROL MECHANISMS. A STUDY DIRECTED TOWARD IMPROVEMENT OF METHODS FOR THE PRECLINICAL EVALUATION OF ANESTHETIC AGENTS
}

\author{
By CARL A. MOYER ${ }^{1}$ AND HENRY K. BEECHER \\ (From the Anesthesia Laboratory of the Harcard Medical School at the Massachusetts \\ Gencral Hospital, Boston)
}

(Received for publication February 9, 1942)

In previous articles the effects of sodium evipal $^{2}$ or sodium pentothal ${ }^{3}$ anesthesia upon the respiratory control mechanisms were described. Both anesthetics depress the central chemical mechanism of breathing (carbon dioxide control) much more rapidly than they depress the peripheral reflex chemical mechanisms (carotid and aortic chemoreflexes) (1), and the vagopulmonary proprioceptive reflexes (Hering-Breuer) (2). These observations are in agreement with the earlier findings of Henderson (3), Marshall and Rosenfeld (4), and Comroe and Schmidt (5) for anesthetic states produced by other barbiturates.

The experiments reported here were planned so that the relative rôles played by carbon dioxide and by oxygen, in the control and maintenance of breathing at different depths of evipal and pentothal anesthesia, could be more fully evaluated. Accordingly, the respiratory responses to a constant increase in the carbon dioxide content, and to a constant decrease in the oxygen content of the inspired air were recorded at three levels of anesthesia. This provided a gross measure of the ability of an animal ( $\operatorname{dog})$ to react to fairly constant chemical stimulation of the respiration. The stimulating agents chosen exhibit certain differences in their sites of action. In addition, the effects of increasing the oxygen tension of arterial blood above that present when the animals breathed room air were studied in order to determine roughly the degree of anoxic chemoreflex activity at different anesthesia levels when the animals were breathing air.

\footnotetext{
1 Fellow of the National Research Council.

2 Sodium evipal is 1 -methyl $5 \Delta^{1}$ cyclohexenyl 5 methyl barbiturate.

${ }^{3}$ Sodium pentothal is ethyl (1-methyl-butyl) thiobarbiturate.
}

It was learned from earlier experiments that as the anesthesia (evipal or pentothal ${ }^{4}$ ) was deepened, breathing became more dependent upon anoxic chemoreflex stimulation without, in many instances, any great change in minute volume of breathing; therefore, it was realized that it was necessary to keep the oxygenation of arterial blood at or above that existing at the beginning of the experiment in order to appreciate even roughly the rate and extent to which the mechanisms involved in hypercapnic hyperpnea were depressed. In order to accomplish this, the anesthesia was increased while the animals breathed pure oxygen. The efficacy of this procedure was checked by frequent determinations of the oxygen content of the arterial blood. The possibility existed that the decreased breathing that normally accompanied deepening anesthesia might have been due to a decreasing rate of carbon dioxide production, as a result of a reduction in the normal oxidations effected by the anesthetic, rather than to a decreased reactivity of the animal to carbon dioxicle. To check this possibility, the carbon dioxide content of the arterial blood was determined at close intervals.

These things were done with the hope that it might thereby be possible to establish certain improved basic methods for evaluating new anesthetic agents before their clinical introduction. Final evaluation of anesthetic agents can be made, of course, only in the clinic, but the wastefulness of present practices, not only in monetary terms but in terms of human lives needlessly lost, offers a stimulating challenge to improve laboratory methods of evaluating anesthetic agents before they are introduced into the clinic.

4 Whenever evipal or pentothal are administered, it is to be understood that reference is made to the soluble sodium salt of the agent. 

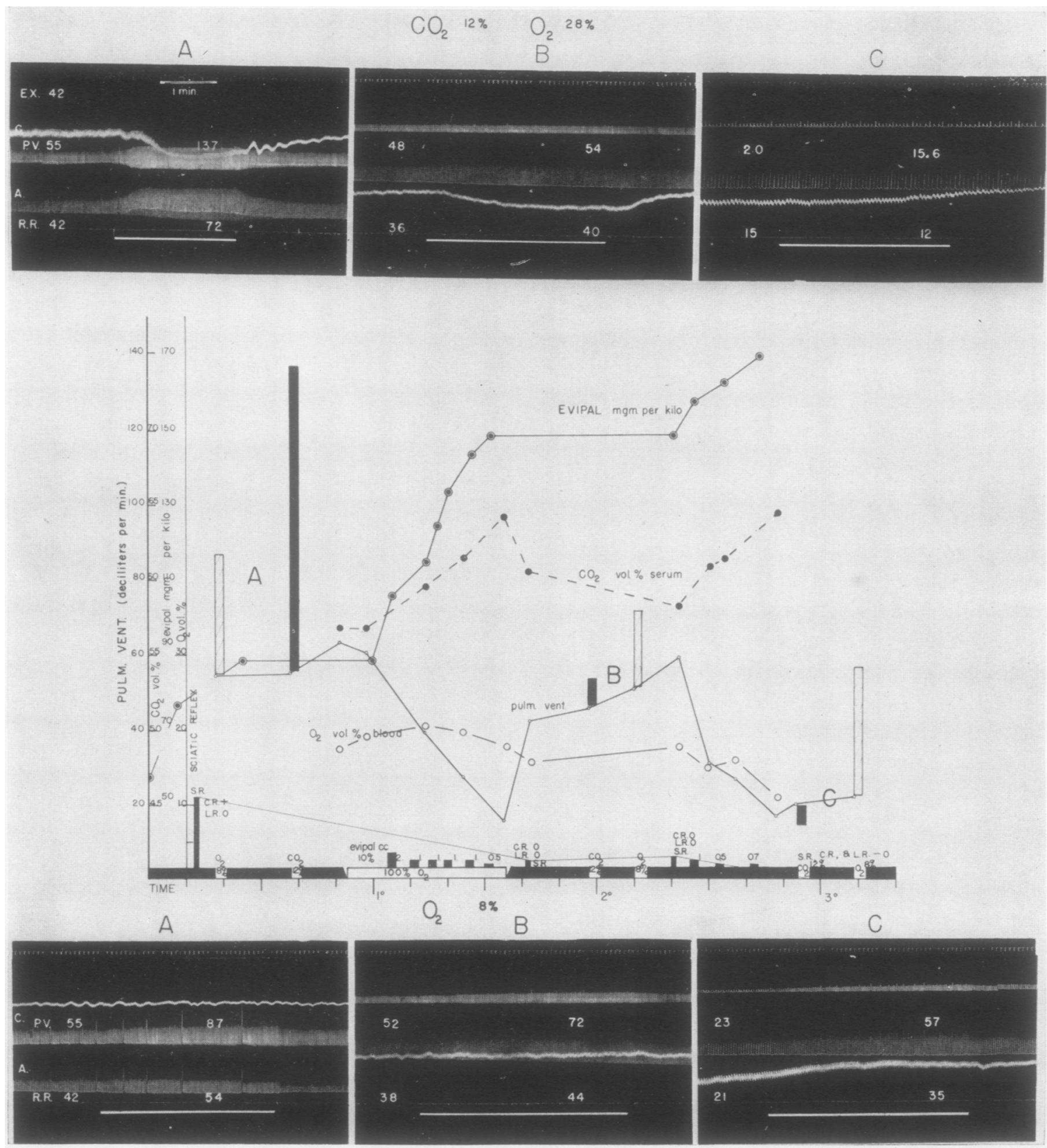

Fig. 1. Time Relationships of the Factors Considered

The kymographic tracings show, from above downward, time in 5 second intervals, costal respiration, the pulmonary minute ventilation (P.V.) in deci-liters (the spirometer tracings of the tidal excursions, used in the calculation of P.V., have been omitted to conserve space), abdominal respiration, blood pressure (at varying positions on the several records, easily differentiated from the respiratory tracings by its smaller excursion and characteristic appearance), respiratory rate per minute (R.R.), a fine base line (used in some subsequent figures to indicate activity of the sciatic reflex, as an objective record of anesthesia depth), a broad line to indicate the interval during which special gas mixtures were administered. The special gas mixtures are indicated above the respective kymograph tracings; it is to be understood that nitrogen adequate to complete the 100 per cent is included with the specified gases.

The chart shows five ordinate scales, from left to right: pulmonary ventilation in deci-liters per minute, carbon dioxide in volumes per cent of arterial serum, dose of evipal in $\mathrm{mgm}$. per $\mathrm{kgm}$. body weight, oxygen in vol- 


\section{METHODS}

The equipment and procedures employed have been described previously (1). Briefly, mongrel dogs weighing about $10 \mathrm{kgm}$. were used as subjects. Data pertinent to the present report were obtained from experiments on 29 dogs; but since these first 29 experiments were directed primarily toward a solution of other although related problems, 8 more dogs were used in which the specific questions raised in this paper were studied. The anesthetic agents studied consisted of sodium evipal [1 methyl $5 \Delta^{1}$ cyclohexenyl 5 methyl barbiturate] in 10 per cent aqueous solution, administered intravenously, and sodium pentothal [ethyl (1 methyl-butyl) thiobarbiturate] in 5 per cent aqueous solution also administered intravenously. Depth of anesthesia was controlled as carefully as possible by observation of records of a flexion reflex (left semitendinosus muscle) elicited by electrical stimulation of the central end of the cut left sciatic nerve. In addition, notes were kept of the state of the corneal (C.R.) and lid (L.R.) reflexes; normal activity was described as $2+$. Three simultaneous records were made of the respiration: tidal, "intercostal," and "diaphragmatic." Arterial blood pressure was recorded by means of a Ludwig manometer connected with the femoral artery. Blood gases were determined in duplicate by the methods of Van Slyke and Neill; oxygen in $1.0 \mathrm{cc}$. samples of heparinized arterial whole blood taken under oil, carbon dioxide in 0.5 cc. of arterial serum, collected under oil.

\section{PRESENTATION OF RESULTS}

The kymographic tracings show from above downward: time in 5 second intervals, costal breathing (upstroke-inspiration), respiratory minute volume in deciliters per minute (the spirometer tracings from which the values of pulmonary ventilation or minute volume were obtained have been omitted to conserve space in all the figures excepting number 9), abdominal respiration, respiratory rate (R.R.), blood pressure (at varying positions on the several records, easily differentiated from the respiratory tracing by its smaller excursion and characteristic appearance), the base line of activity of the sciatic reflex (see Figure 9), a broad white inked line to indicate the interval during which special gas mixtures were administered, and blood pressure base line (all the records excepting that in Figure 9 were cut along the corrected base line for blood pressure). The special gas mixtures $\left(\mathrm{CO}_{2}, 12\right.$ per cent and $\mathrm{O}_{:}, 28$ per cent, and $\mathrm{O}_{\text {:., }} 8$ per cent) are indicated above the respective kymo- graph tracings; it is to be understood that nitrogen completed the 100 per cent.

The graphs in the illustrations (1 to 8 inclusive) show the time relationships of all the procedures of the experiments. The ordinate scales are five in number and are from left to right as follows: pulmonary ventilation (respiratory minute volume) in deciliters per minute, carbon dioxide in volumes per cent of arterial serum, the additive amount of evipal or pentothal in $\mathrm{mgm}$. per $\mathrm{kgm}$. of body weight (exact placement of this ordinate varies in different figures), oxygen in volumes per cent of arterial blood, and height of the reflexly excited contraction of the semitendinosus muscle in $\mathrm{mm}$.

The abscissa shows: the time relationships of the experiments (the unit interval represents 10 minutes); the gas mixture breathed (solid black designates the periods when room air is respired, the short unroofed open blocks labeled $\mathrm{O}_{3}, 8$ per cent and $\mathrm{CO}_{3}, 12$ per cent delimit the periods of the low oxygen or carbon dioxide administrations, and the completely enclosed clear blocks represent the periods when oxygen was breathed); and the number of cc. of evipal (10 per cent) or pentothal ( 5 per cent) injected.

The solid bar graphs (S.R.) based on the abscissa denote the heights of contraction of the semitendinosus muscle. The fine line that connects the tops of these bars grossly indicates the trend of anesthesia, a falling line indicates greater depth.

The bar graphs based on the line designated "pulm. vent." represent when solid, carbon dioxide hyperpnea, and when cross hatched, low oxygen hyperpnea, measured as the increase in minute volume of breathing obtaining at the end of the third minute of the carbon dioxide or low oxygen administration, over the normal minute volume of breathing for the last three minutes of eupnea, excepting in experiment 43, Figure 4, in which the normal was taken as the minute volume of breathing, during the seventh minute after the carbon dioxide administration was terminated because of the failure of the animal to return to the apneustic type of respiration that prevailed before the period of hypercapnia. The records, excepting the spirometer tracings from which the data for these later bar graphs were obtained, are shown above (carbon dioxide) and below (low oxygen) their graph placements; these records do not coincide at the positions A, B, or $\mathrm{C}$ but lie on either side of them. The data, from which the line graph labeled "pulm. vent." was constructed, was obtained from the spirometer record of tracings taken of breathing after a grossly steady rhythm had been attained and before changes in experimental condi-

umes per cent of arterial whole blood. The sciatic reflex activity is indicated in mm. contraction of the semitendinosus muscle. The state of the corneal (C.R.) and lid (L.R.) reflexes is shown.

The abscissa is used to show time relationships, the intervals (and dose) at which the anesthetic agent was administered, and the particular gas mixtures inspired. Room air was inspired except as specified.

The bar graphs in the body of the figure indicate when solid, carbon dioxide hyperpnea (refer to pulmonary ventilation ordinate); when cross-hatched, low oxygen hyperpnea; the height of each of these indicates the increase over "normal" is a result of the particular stimulant. The letters A, B, C, identify on the graph the position of the kymographic data shown. 

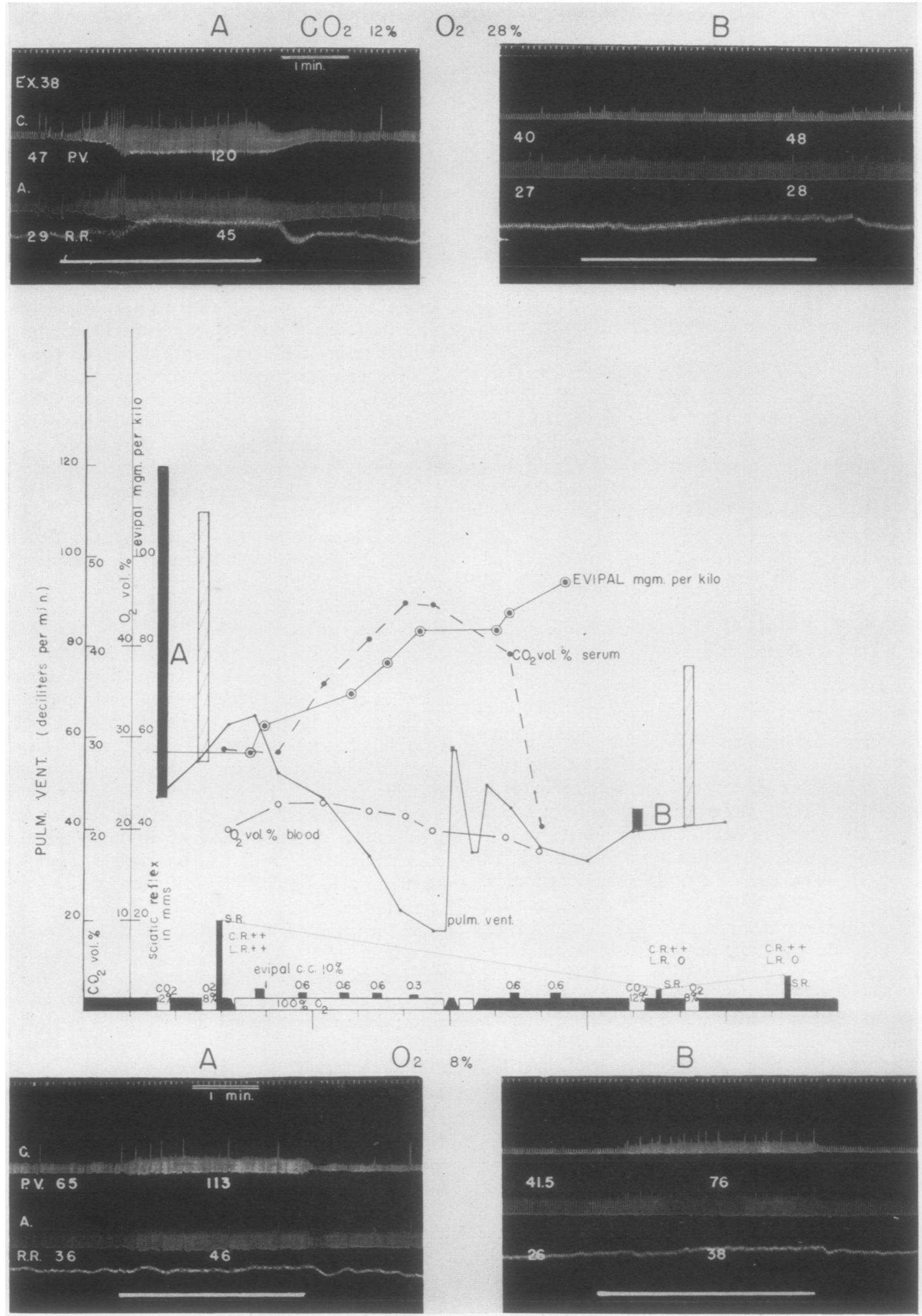

Fig. 2. Legend AS For Figere 1 


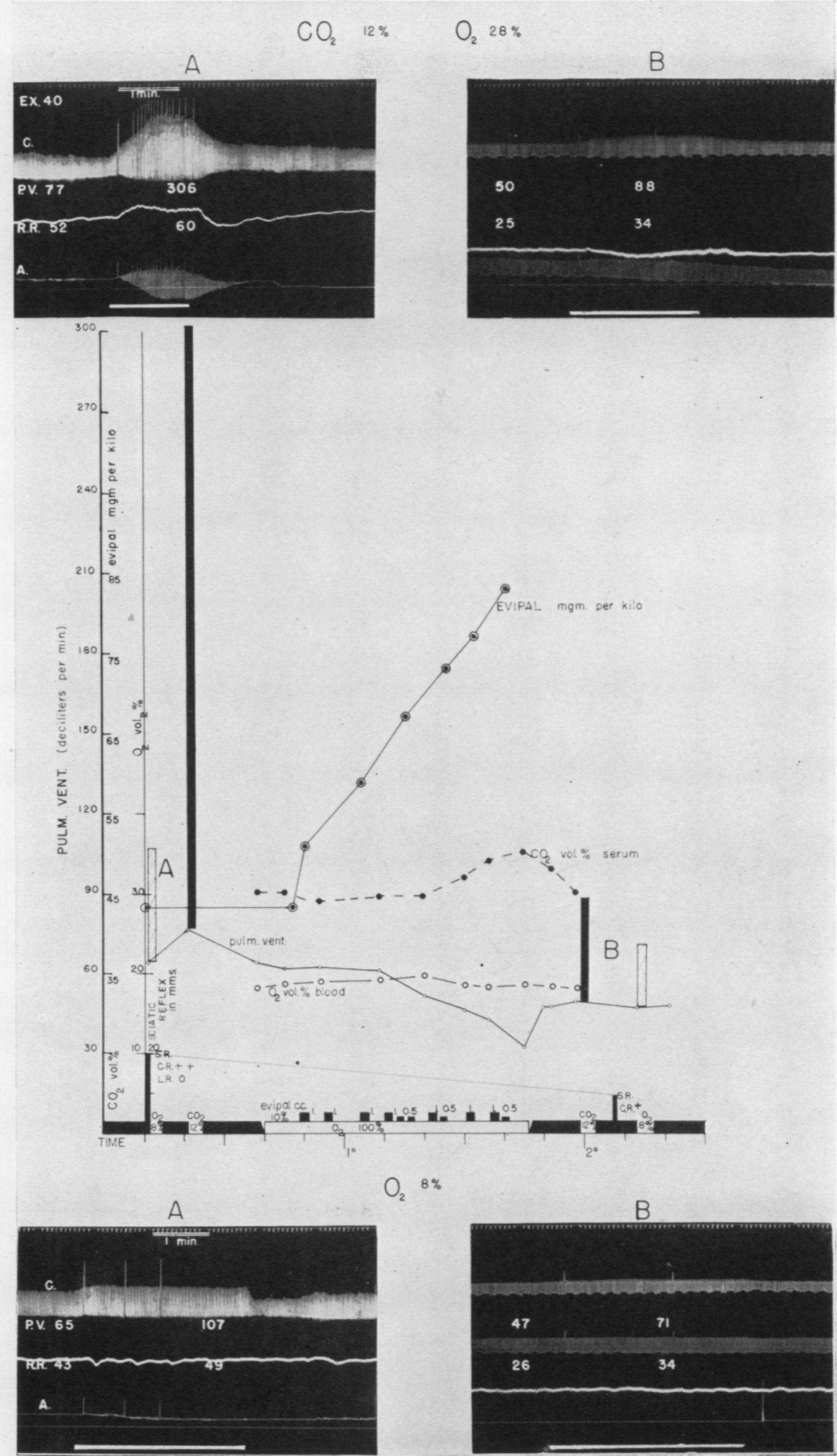

Fig. 3. Legend as for Figure 1 

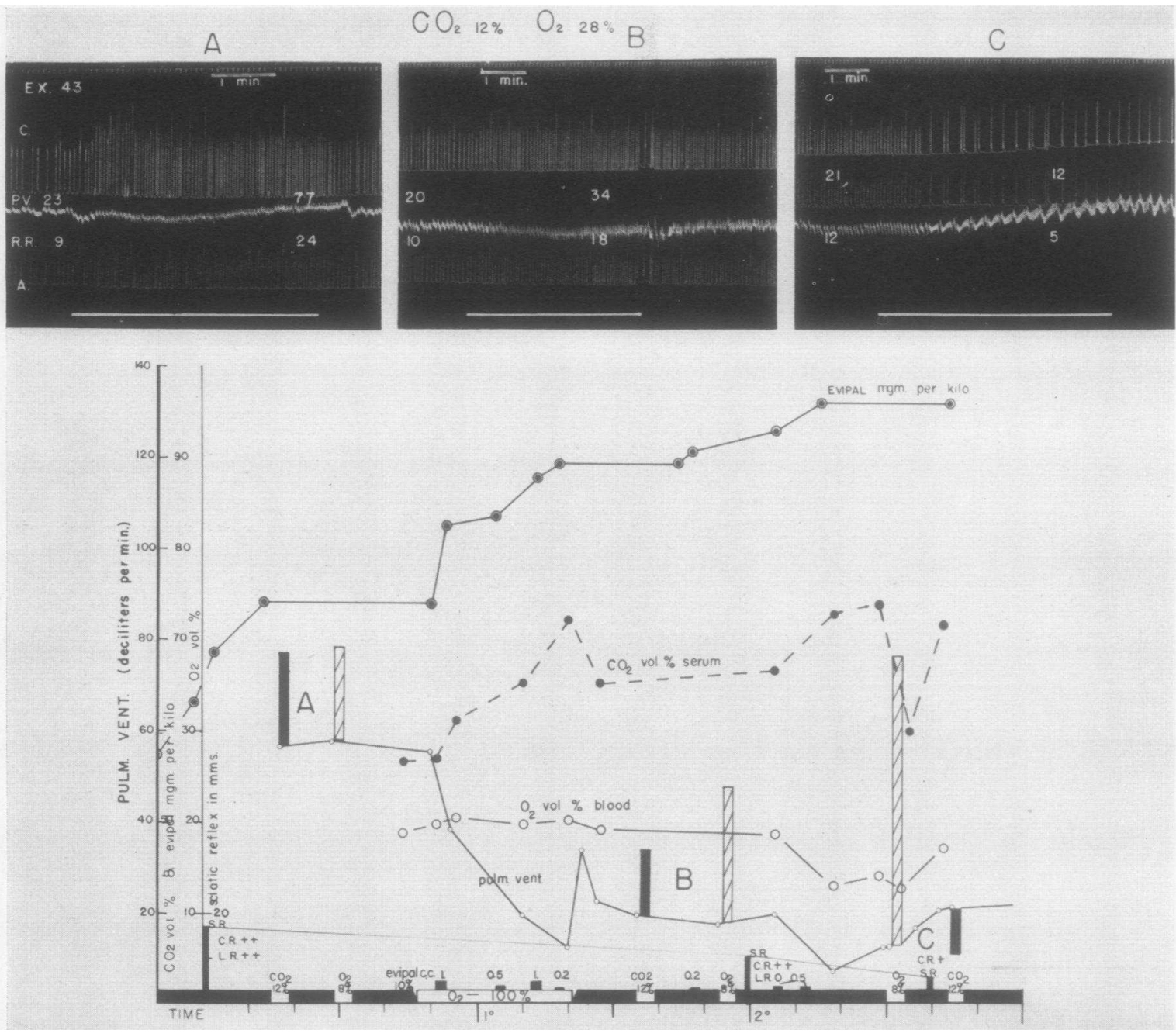

A

$\mathrm{O}_{2} \quad 8 \% \quad \mathrm{~B}$
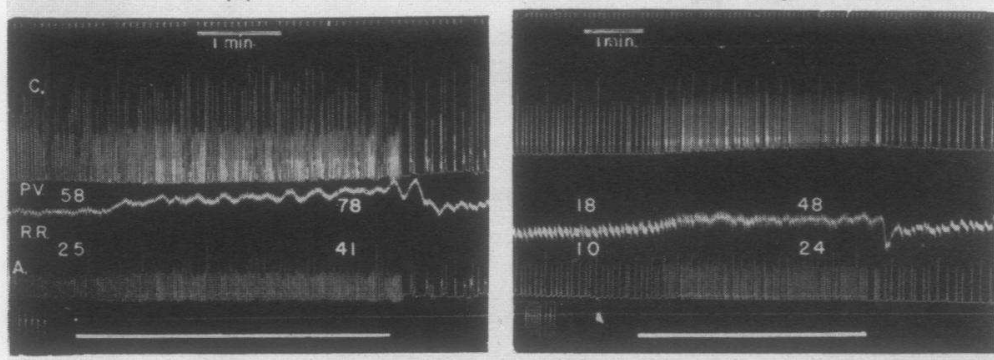

C
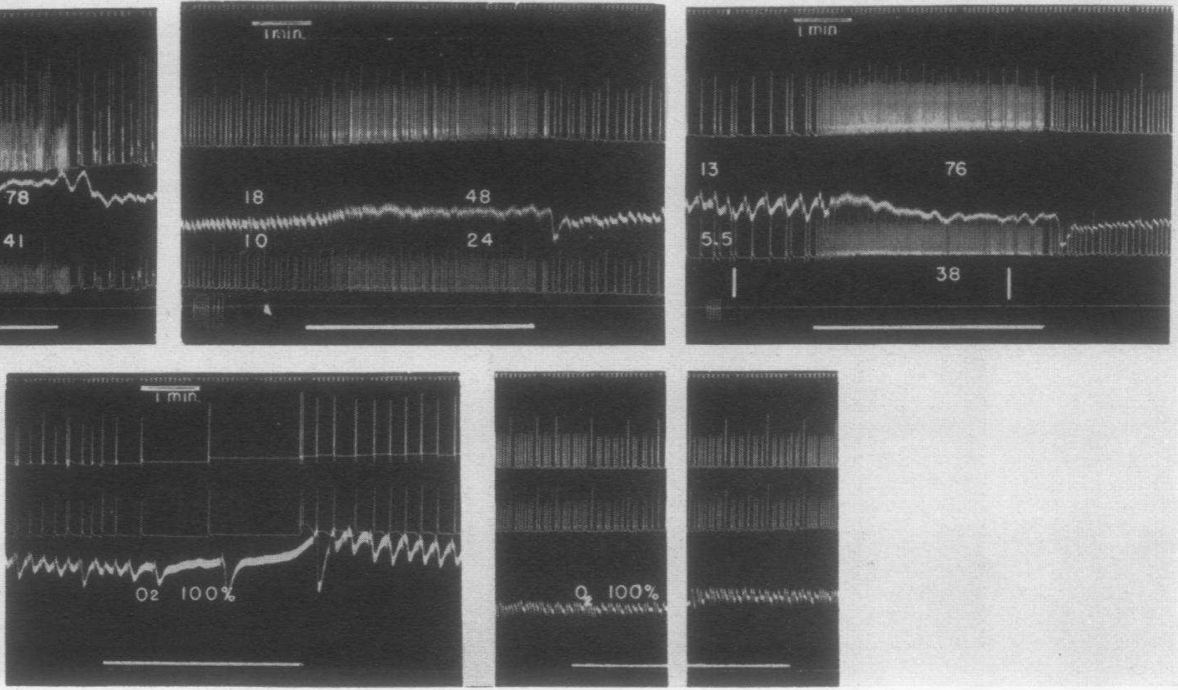

Fig. 4. Legend as fOR Figure 1 
tions were made (the administration of oxygen or air, the injection of anesthetic, or the withdrawal of arterial blood samples, etc.). It is evident that evipal (Figures 1 to 4 ) and pentothal (Figures 5 to 8 ) exert a much greater depressant effect on hypercapnic hyperpnea than upon anoxic hyperpnea. In three instances (Figures 1, 4, and 6) carbon dioxide changed from a powerful respiratory stimulant to a depressant. The depressant action does not require that a high degree of anoxemia preexist; the oxygen content of the arterial blood in one instance was normal just before the depressant effect of carbon dioxide was elicited (Figure 4, experiment 43).
In order to obtain clearer information as to the rapidity with which central sensitivity to carbon dioxide was reduced as previously mentioned, evipal and pentothal were given while the animals breathed 100 per cent oxygen in order to keep the chemosensitive reflex mechanisms as inactive as possible. The anesthesia was always very light when this change was first effected. Arterial blood oxygen content rose 0.4 to 3.3 volumes per cent, but arterial carbon dioxide did not change significantly when 100 per cent oxygen was given (Table I). It rose, however, as more anesthetic was given. With each injection of evipal or pentothal while the animal breathed oxygen, the minute

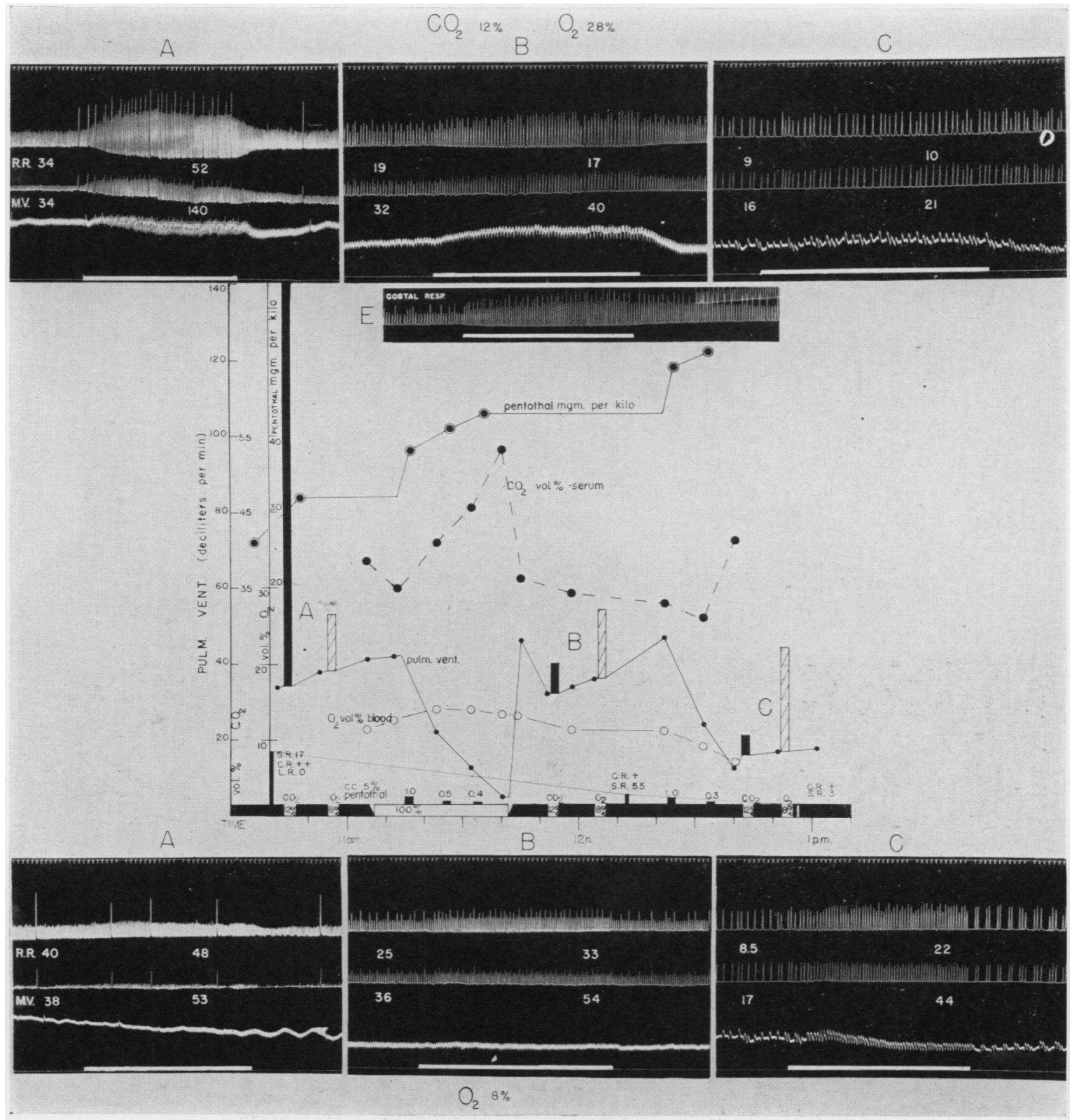

Fig. 5. Legend As For Figure 1 


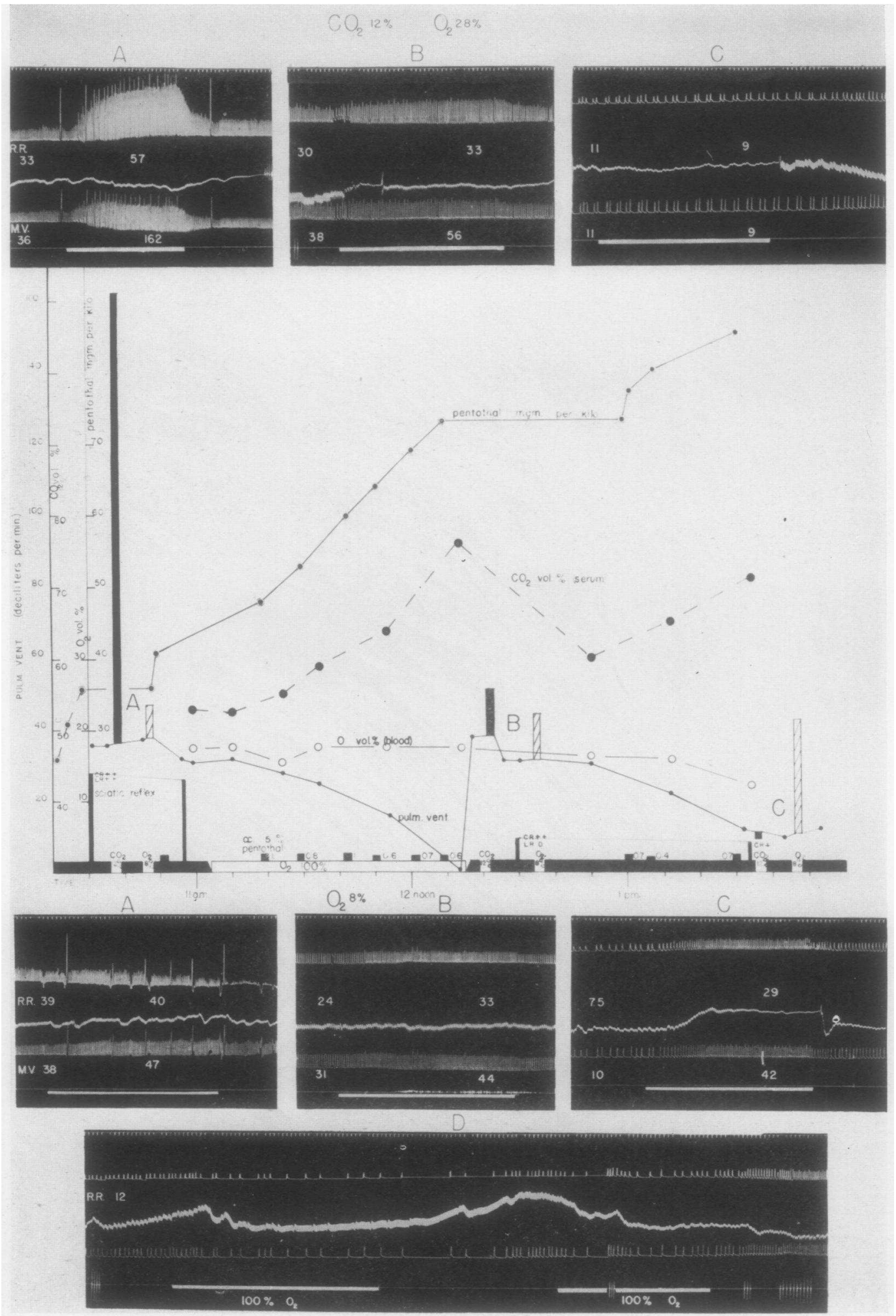

Fig. 6. Legend as for Figure 1 
volume of breathing fell, mainly as a result of a slowing of rate. (The evipal and pentothal injections are shown in bars along the abscissa; the additive quantity of drug in $\mathrm{mgm}$. per $\mathrm{kgm}$. is represented as a line graph.) The individual variation to evipal or pentothal, as determined by the variability between the decreases in minute volume of breathing per $\mathrm{mgm}$. of drug per $\mathrm{kgm}$., is great even in these very small series. Compare Figures 1 with 2, and 5 with 8 .
With the decrease in minute volume of breathing, serum carbon dioxide rose indicating that breathing was depressed by evipal and pentothal more rapidly than was the rate of carbon dioxide formation, if indeed the latter was at all affected at the anesthesia level concerned. The expedient of administering 100 per cent oxygen to keep the level of anoxic chemoreflex respiratory stimulation at or below normal limits was fairly successful, for in only two experiments (46 and 52) did the arterial oxygen con-
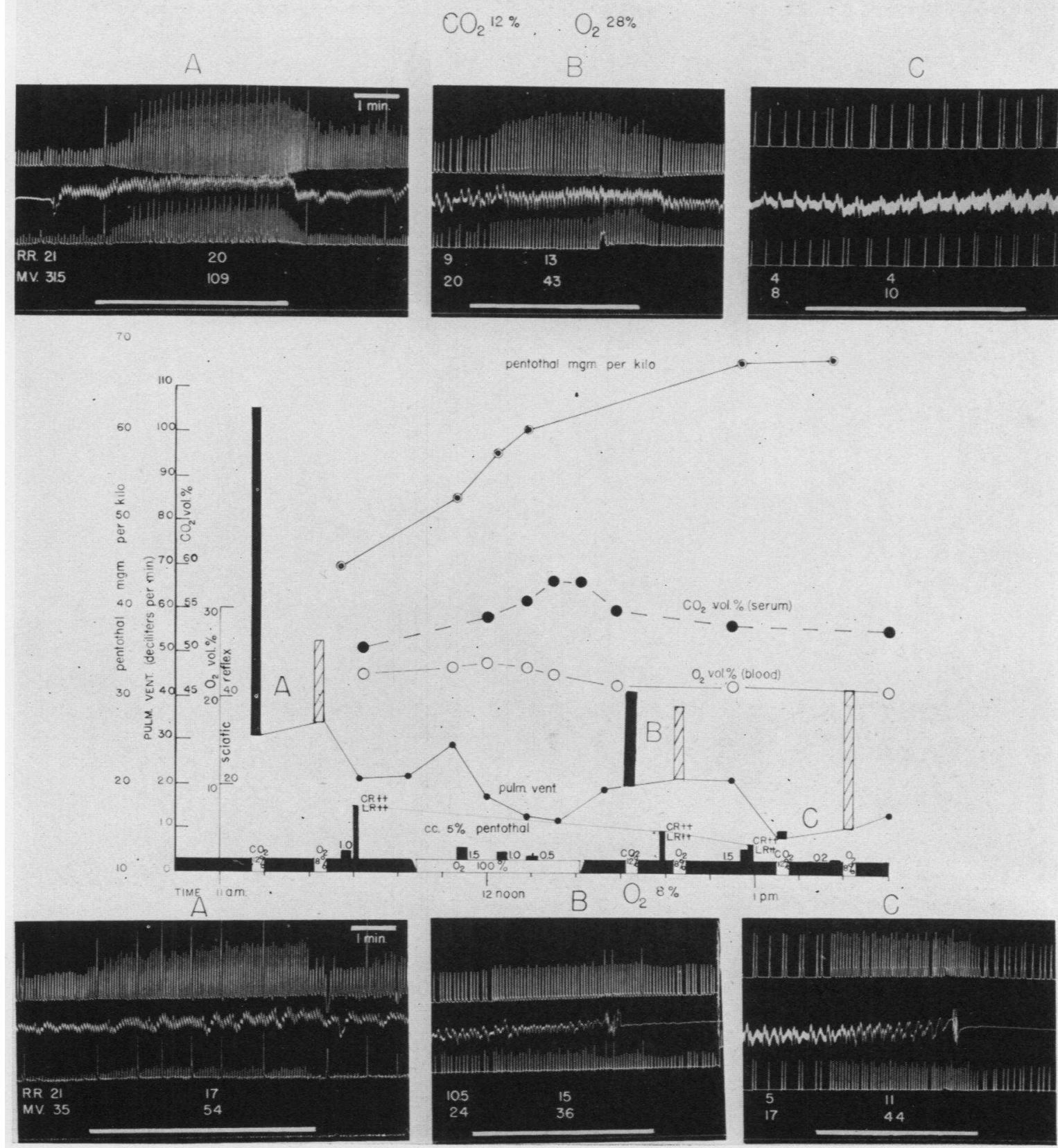

Fig. 7. LEGEND AS FOR FigUre 1 


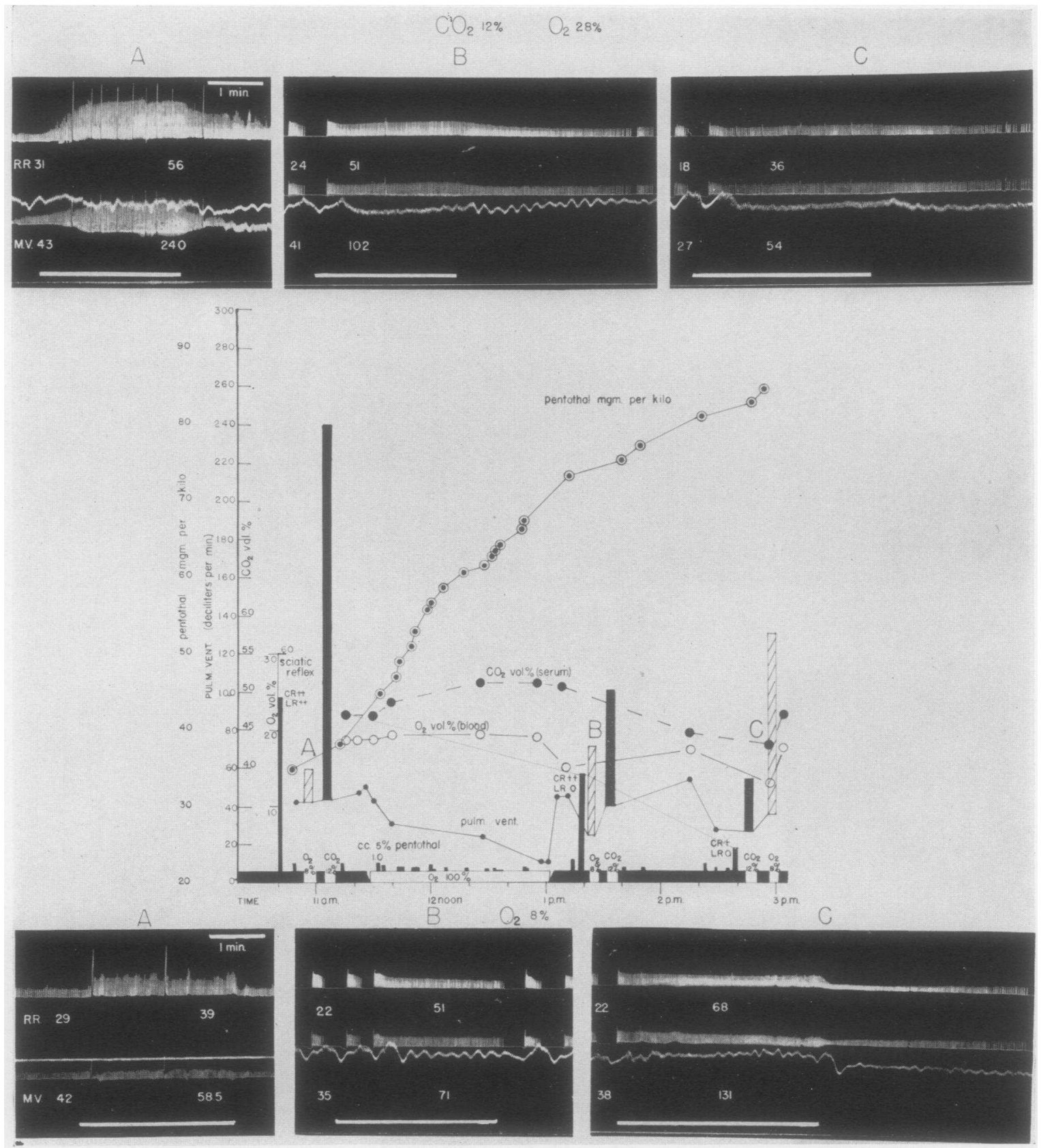

Fig. 8. Legend as for Figitre 1

tents fall below the control value, in spite of reductions in minute volume of breathing. When room air was again administered, breathing quickly increased. The increases in minute volume of breathing were associated with decreases in arterial carbon dioxide and oxygen contents (Table I).

\section{DISCUSSION}

It appears, from the evilence gained from these experiments, that the breathing of an ani- mal very lightly anesthetized with evipal or pentothal is primarily regulated by the need for carbon dioxide removal and not especially by need for oxygen, which agrees with the findings of Haldane (6) and others in normal man and animals. If respiration was being regulated substantially by oxygen need, then slowing of breathing should have been the rule when the arterial oxygen tension was increased. The oxygen content of arte- 
TABLE I

Arterial $\mathrm{O}_{2}$ volumes per cent

\begin{tabular}{|c|c|c|c|c|c|c|}
\hline \multirow{2}{*}{$\begin{array}{l}\text { Expe:i- } \\
\text { ment } \\
\text { number }\end{array}$} & \multicolumn{2}{|c|}{$\begin{array}{c}\text { Anesthesia } \\
\text { Light }\end{array}$} & \multicolumn{2}{|c|}{$\begin{array}{l}\text { Anesthesia } \\
\text { Moderate }\end{array}$} & \multicolumn{2}{|r|}{$\begin{array}{l}\text { Anesthesia } \\
\text { Deep }\end{array}$} \\
\hline & & $\begin{array}{l}\text { 1st. de- } \\
\text { term. } \\
\text { during } \\
100 \text { pe: } \\
\text { cent } 0_{2}\end{array}$ & $\begin{array}{l}\text { Last de- } \\
\text { te } \cdot \mathrm{m} . \\
\text { du ing } \\
100 \text { per } \\
\text { cent } \mathrm{O}_{2}\end{array}$ & $\begin{array}{l}\text { 1st. de- } \\
\text { term. } \\
\text { after } \\
100 \text { per } \\
\text { cent } \mathrm{O}_{2}\end{array}$ & $\begin{array}{l}\text { Last } \\
\text { de- } \\
\text { term. } \\
\text { air }\end{array}$ & $\begin{array}{c}\text { Minute volume increase } \\
\text { (lite:s) when shifted } \\
\text { from } 100 \text { per cent } \\
\mathrm{O}_{2} \text { to air }\end{array}$ \\
\hline $\begin{array}{c}\text { Evipal } \\
38 \\
40 \\
42 \\
43 \\
\text { Pentothal } \\
44 \\
46 \\
52 \\
53\end{array}$ & $\begin{array}{l}20.0 \\
16.9 \\
17.5 \\
19.0 \\
\\
12.7 \\
17.1 \\
22.0 \\
17.8 \\
\text { Air }\end{array}$ & $\begin{array}{r}23.3 \\
17.5 \\
19.3 \\
20.0 \\
14.0 \\
17.8 \\
22.5 \\
18.2 \\
\text { Oxygen-1 }\end{array}$ & $\begin{array}{c}20.0 \\
17.0 \\
17.9 \\
20.4 \\
\\
13.4 \\
16.4 \\
21.5 \\
17.8 \\
\text { 00 per cent }\end{array}$ & $\begin{array}{l}17.7 \\
17.0 \\
15.7 \\
19.3 \\
\\
13.2 \\
15.8 \\
21.0 \\
15.4\end{array}$ & $\begin{array}{r}15.5 \\
17.3 \\
7.1 \\
12.0 \\
20.0 \\
17.2\end{array}$ & $\begin{array}{l}2.7 \text { in } 6 \text { minutes } \\
1.3 \text { in } 4 \text { minutes } \\
2.7 \text { in } 2 \text { minutes } \\
2.1 \text { in } 3 \text { minutes } \\
4.2 \text { in } 4 \text { minutes } \\
3.5 \text { in } 3 \text { minutes } \\
3.3 \text { in } 2 \text { minutes } \\
0.7 \text { in } 7 \text { minutes }\end{array}$ \\
\hline
\end{tabular}

Arterial $\mathrm{CO}_{2}$ volumes per cent

\begin{tabular}{c|c|c|c|c|c|c}
\hline $\begin{array}{c}\text { Evipal } \\
38\end{array}$ & 28.9 & 28.5 & 44.8 & 39.4 & & \\
40 & 45.7 & 45.5 & 50.2 & 45.4 & & \\
42 & 58.8 & 58.2 & 73.8 & 66.4 & 74.3 & \\
43 & 56.8 & 57.1 & 72.1 & 65.3 & 73.4 & \\
Pentotha! & & & & & \\
44 & 37.0 & 31.9 & 53.0 & 36.1 & 42.4 & \\
46 & 53.0 & 52.6 & 76.4 & 60.2 & 71.3 & \\
52 & 50.0 & 54.0 & 58.0 & 54.5 & 53.0 & \\
53 & 46.5 & 47.8 & 51.0 & 50.0 & 48.0 & Air \\
& Air & \multicolumn{2}{|c|}{ Oxygen-100 per cent } & \multicolumn{2}{|c|}{} \\
\hline
\end{tabular}

rial blood increased 0.4 to 3.3 volumes per cent and the carbon dioxide content of the arterial serum did not change in these experiments under light anesthesia when 100 per cent oxygen was substituted for room air; in only 2 of the $8 \mathrm{ex}$ periments was there a significant sustained decrease in rate or amplitude of breathing associated with this increased oxygenation. Pertinent supporting data can be found in the observation that minute volume of respiration necessary for the maintenance of a normal arterial oxygen content of some anesthetized animals at sea level is less than that necessary to effect removal of carbon dioxide. This becomes eviclent in these studies only after the respiratory center's sensitivity to carbon dioxide is reduced, as in experiment 43 , Figure 4. When the animal after being more deeply anesthetized is breathing room air, an arterial oxygen content is maintained at the normal level by one-third the minute volume that was present when the animal was lightly anesthetized, but the arterial carbon dioxide continues to increase at this lowered level of ventilation.

As the evipal anesthesia is moderately deepened, breathing is seemingly regulated by both carbon dioxide and oxygen need. At this stage
100 per cent oxygen visibly slows breathing and carbon dioxide is still able to stimulate it. The intermediate stages (B) of experiments 1 to 8 illustrate this point. Carbon dioxide inhalations still stimulate breathing appreciably and the decrease in arterial oxygen content of from 0.2 to 2.4 volumes per cent that follows the shift from 100 per cent oxygen to room air is associated with minute volume increases varying between 0.7 to 4.2 liters per minute. If pure oxygen is administered again, the pulmonary exchange decreases [Figures 2 (above second clear block of abscissa) and 4 (lower right kymographic record)].

When the anesthesia is deepened, further breathing becomes increasingly dependent upon arterial oxygen content, since carbon dioxide becomes less capable of stimulating breathing and instead occasionally depresses it (Figures 1, 4, and 6 ). Increase in the oxygen content of the arterial blood now slows respiration dangerously. This is shown in Figures 4 (lower left) and 6.

Mechanisms evidently playing the major rôle in maintenance of breathing, after central sensitivity to carbon dioxide is obliterated, are the carotid and aortic chemoreceptors $(4,7,8)$. At this stage of anesthesia it is probable that the chemoreceptor mechanisms have a lower threshold to oxygen lack stimulation than does the center, which is in complete accord with the findings of Heymans (9) and others. This evident shift in maintenance of cupncic breathing, from the action of carbon dioxide upon the automatically rhythmical center to control by the chemosensitive reflex mechanisms activated by anoxia, is in many instances unattended by changes in the rate or character of breathing, or changes in blood pressurc, which might afford us objective means of determining when the shift takes place. Therefore, the anesthetist has no means of knowing the status of the respiratory control mechanisms zehen imploying evipal or pentothal.

These experiments permit some insight into possible interrelations of the unanesthetized center and chemoreceptors in the regulation of breathing during hypoxia. In 6 of the experiments illustrated here, the stimulation of breathing by a constant degree of hypoxia increased as the anesthesia was deepened. This takes place occasionally when evipal or pentothal is injected during the hypoxic hyperpnea (3 of 10 experiments with evipal and 
2 of 4 experiments with pentothal). Figure 9 illustrates this phenomenon. The increased effectiveness of the decreased oxygen tension is shown as the center's sensitivity to carbon dioxide decreases.

The increased effectiveness of anoxia as a respiratory stimulant, as the level of evipal or pentothal anesthesia is cleepened, might indicate that these agents have the power of increasing reflex excitability; however, the lid and corneal reflexes and the electrically excited reflex contraction of the semitendinosus muscle are progressively depressed as the anesthesia is deepened ; so the idea that evipal and pentothal increase goncral reflex excitability is apparently untenable. at least at the levels studied. There remain three alternative explanations: 1 , that evipal and pentothal serve as excitants of the chemoreceptors; 2 . that they depress a central restraining mechanism more rapidly than they depress the peripheral receptors ; 3 , or both.

Regardless of what the fundamental reasons for this phenomenon are, it is obvious that the extensive changes in the control of breathing that attend relatively small variations in the anesthetic state induced by evipal and pentothal should serve as indications, that far greater care in the control of anesthesia should be taken in physiologic experimental work than has heretofore been the practice. More attention should be paid to the objective recording of depth of anesthesia in so far as this is possible and the agent employed in experimental work should be of such a nature as to permit the adjustment of dosage upon the basis of biological effect, rather than body weight. It is also obvious that data obtained in experiments conducted upon anesthetized animals cannot be taken as a basis for determining the relative importance of the several respiratory mechanisms in the maintenance and control of breathing in an unanesthetized subject. The great amount of experimental work done on anesthetized animals in attempts to determine the relative rôles played by the respiratory center and the peripheral chemoreflexes has resulted in much confusion. The anesthetic agents often used in the past are varied : ether, chloralose, a combination of morphine and urethane, a combination of morphine and ether and chloralose are only a few of the examples to be found in the literature. When the differences in the funclamental pharmacological actions of the various anesthetics are considered, reasons are apparent for the variance of opinions between investigators, and of individual investigators from year to year.

Considering the experimental findings from the standpoint of general anesthetic action, evipal and pentothal are substances which, when used to anesthetize a dog. depress that animal's reactivity to carbon dioxide far more than they do the chemoreceptive and pulmonary vagal proprioceptive respiratory reflexes. As a result of this action, the regulatory powers of the center over the reflexes and the regulation of breathing on the basis of need for carbon dioxide removal by the center is obliterated in many animals, at a level of anesthesia which is unattended by muscular relaxation and which often will not allow traumatic surgery ( $c . g$., denervation of carotids) without great stimulation of respiration and at times general somatic movements. The maintenance of breathing under moderate to deep evipal or pentothal anesthesia then frequently becomes dependent upon reflex respiratory mechanisms, the most important being the carotid and aortic chemoreceptors. This transition from a central to a peripheral chemical control of breathing is attended by a partial loss of respiratory acid-base regulation. If the carotid and aortic bodies were cffective participants in the regulation of acid-base balance under $d e c p$ evipal or pentothal anesthesia, one should expect them to increase breathing whenever blood carbon dioxide increases. This is obviously not the case (Figures 1, 4, and 6). All of these animals responded actively to hypoxia at the deep stage of anesthesia. Such a reaction is undoubtedly mainly, if not entirely, of reflex origin " $(7,9,10,11)$, but at such a level of anesthesia carbon dioxide was a depressant. Figures 4 and 6 demonstrate that the lowered oxygen content of the arterial blood accounts for the reflex stimulation of breathing, for when the content was raised the respiration slowed. It appears that the carotid and aortic reflex mechanisms of an animal, moderately to deeply anesthetized with evipal or pentothal, are not as capable of effecting respiratory adjustments to increasing carbon cli-

\footnotetext{
5 Hypoxia is an effective central stimulant only under light barbiturate anesthesia. See Moyer and Beecher, Am. J. Physiol., 1942, 136, 13.
} 

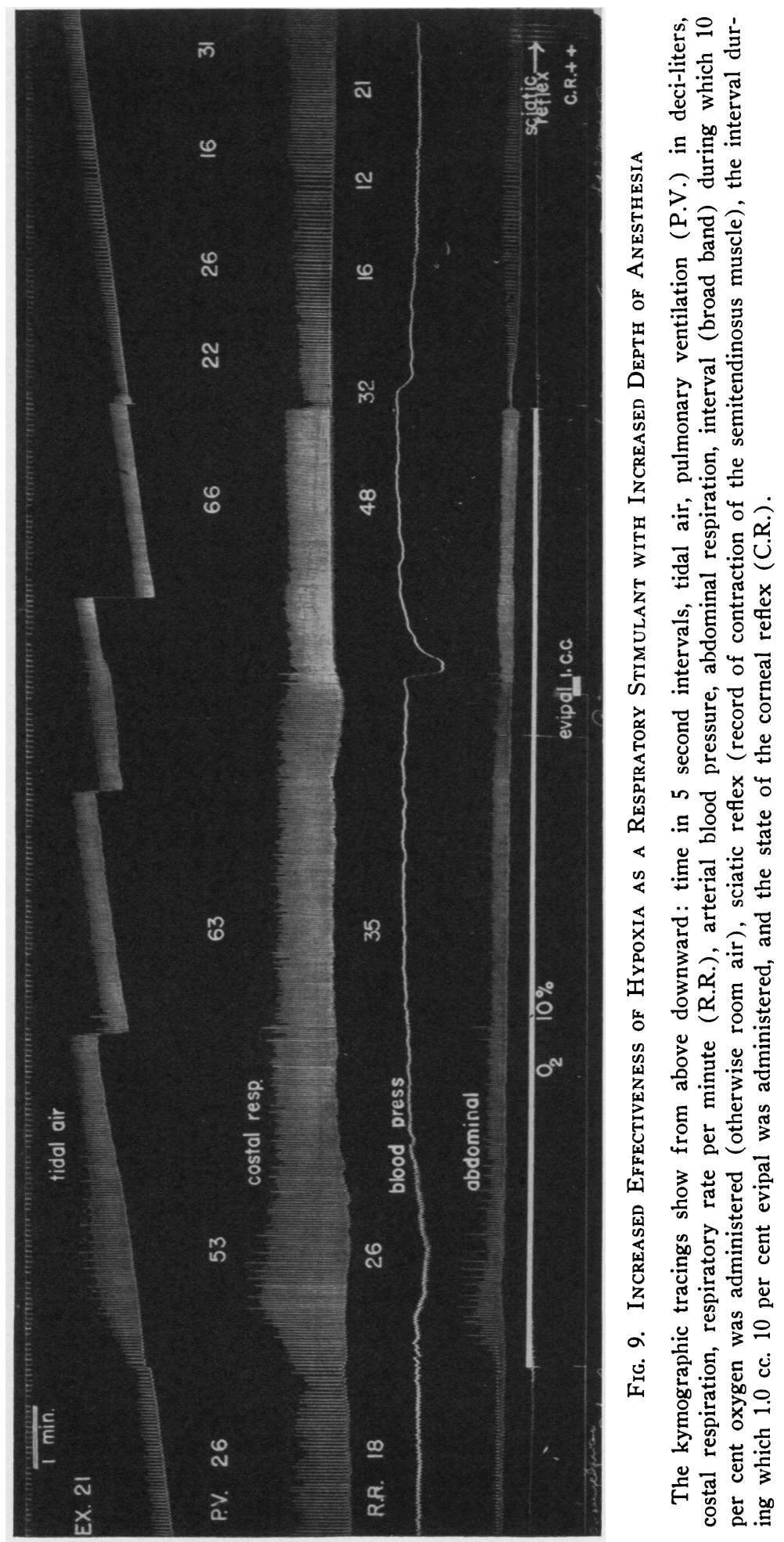
oxide content of the arterial blood, as they are to effecting adjustments to decreased oxygen contents and tensions. This does not imply that the carbon dioxide is not stimulating the glomus endings, for Samaan and Stella (12) and von Euler, Liljestrand, and Zotterman (13) have shown increasing discharges in Hering's nerve as carbon dioxide is increased in the arterial blood. It is possible that carbon dioxide blocks the propagation of the impulses by its reflex depressant action $(14,15,16)$.

The significant changes in the control of breathing that attend small variations in anesthetic states induced by evipal or pentothal are not apparent from the determination of the relationship of dosage to respiratory minute volume of breathing while the animals breathe air. The usual methods of determining whether an anesthetic is of probable clinical value leave too much to be learned concerning its pharmacologic action during its clinical employment with a relatively large expenditure of effort, time, and human life. This is apparently in part dependent upon the difficulty of anticipating, ahead of clinical use, the multiplicity and extent of the demands placed upon the agent by the surgeon and the anesthetist, and to general lack of recognition of the extent to which alterations in physiologic state inciclent to disease, medication, and surgery may affect the toxicity of the anesthetic. Lives might well have been saved had it been known when evipal and pentothal were introduced into the clinic, that hypercarbia and anoxia increase the toxicity of these agents (1) and that low blood oxygen can mask the true level of anesthesia (1). Hyperoxia (oxygen content of inspired gas greater than that of air), for reasons previously discussed. increases the respiratory toxicity of evipal and pentothal. In Figures 1 to 8 inclusive it is clear that less barbiturate is needed to effect a given decrease in minute volume of breathing when oxygen is breathed than when air is breathed. This was not known when the anesthetist first used evipal and pentothal and the fear of the anoxia, that was indicated by the frequent appearance of cyanosis during the course of this anesthesia, rightly prompted the administration of high oxygen concentrations in the inspired air. However, the breathing of oxygen during evipal and pentothal anesthesia, as a consequence of the reduction of the sensitivity of the respiratory center to carbon dioxide by the drugs, coupled with the reduction of the chemoreflex stimuli by the increased oxygenation of arterial blood, results in hypopnea with a retention of carbon clioxide by the body as indicated by the rise in the carbon dioxide content of the arterial blood (Table I). During the period of oxygen administration the arterial oxygen content was either at or slightly above the normal and cyanosis consequently never developed (Table I). Therefore, oxidations, as far as an anesthetist could determine, were never jeopardized; however, the retention of carbon dioxide that occurred without an external sign may well have depressed cellular oxidations more than the direct oxygen lack that may have occurred if room air had been breathed. Furthermore, the retention of carbon dioxide cluring the oxygen administration probably increases the toxicity of evipal and pentothal more than would the usually minor degree of anoxia that is incurred when room air is breathed. It is, therefore, apparent that the adoption of a seemingly simple, effective, and innocuous procedure by the anesthetist, without knowing its effect upon the homeostasis of an organism under the particular circumstances under which it is employed. may result in changes of body economy that are potentially more dangerous without external sign than those with external signs, that prompt the use of the measure.

The clata available here constitute an inadequate basis for the predetermination of the entire possible range of satisfactory application of evipal and pentothal in clinical practice; however, by correlating early clinical findings with these experimental data, a more satisfactory, although incomplete, field of use can be estimated than was previously possible.

For abdominal surgery muscular relaxation is desired by the surgeon. This does not mean merely that it is desirable that muscle tonus be decreased, but also that muscular contraction does not follow the sensory nerve stimulation of the surgeon's manipulations. The palpation of the intact abdomen of an animal during anesthesia gives little practical information concerning the degree of relaxation present at a certain depth of 
anesthesia. Since contraction of muscle elicited by the surgeon's procedures depends upon the integrity of the reflex arc, a basic approach to the problem must include a determination of the relationship between the depression of reflex excitability and the depression of breathing and circulation per unit of drug.

Experimentally, the reflexly excited contraction of the semitendinosus muscle and the vagopulmonary reflexes excited by lung volume changes were not completely suppressed by evipal or pentothal before respiration failed. At a moderate level of anesthesia there was usually only a relatively small decrease in reflex excitability (muscle, corneal, lid, and vagopulmonary reflexes). However, at a moderate depth of anesthesia the abdomen felt relaxed but a firm, quick, point pressure (tip of finger) was quickly followed by tensing of the muscles under the finger. In short, complete muscular relaxation could not be obtained with evipal or pentothal without unduly endangering life from respiratory failure. This statement is supported by clinical observation: pelvic examinations are unsatisfactory under even deep pentothal anesthesia because of the contraction of the muscles of the abdomen and pelvic diaphragm when manual pressure is applied; relaxation of the anal sphincter and of the rectus muscles does not approach that obtained with spinal anesthesia; and the laryngeal reflexes are depressed sufficiently for tracheal intubation only in deep anesthesia. It is, therefore, probable that a degree of muscular relaxation that is readily and safely attainable with ether or spinal anesthesia is made impossible here by the danger of respiratory arrest. The use of pentothal or evipal for abdominal and much rectal surgery cannot therefore permit the surgeon to work with the facility that is afforded by other agents at a safer level of anesthesia. The range of utility of evipal and pentothal in thoracic surgery as suggested by experimental work is very narrow (2).

The safety of an anesthetic also depends in a large measure upon the constancy of the early signs of overdosage that enable the anesthetist to take appropriate measures before respiratory or circulatory depression becomes severe and consequently more dangerous. Under evipal and pentothal anesthesia the corneal and lid reflexes are frequently elicitable in dogs and in man in deep anesthesia, and are occasionally present (in dogs) after respiratory arrest has been produced. With evipal, some depression of costal breathing usually takes place before respiratory arrest (Figures 1 to 4); this occurs infrequently with pentothal (Figures 5 to 8 ). A decrease in minute volume of breathing that can be grossly detected does not occur with constancy between light and deep levels of anesthesia. It is not unusual to have the rate and minute volume of breathing increase as more drug is given, especially if anoxia is present. The eye signs and respiratory signs that ordinarily help guide the anesthetist are not sensitive enough or constant enough under these agents, in the various circumstances that may be encountered, to use them as a very dependable gauge in determining the depth of anesthesia or the imminence of respiratory arrest. Furthermore, if anoxia is present, overdosage is frequently completely masked until an acute and severe respiratory depression develops (1). Overdosage is also masked by sensory nerve stimulation (17), and partial pneumothorax (18). An anesthetist is therefore severely handicapped when employing these agents, largely because evipal and pentothal do not adequately depress certain reflexes before a dangerously deep level of anesthesia has been attained.

It is hoped that this brief consideration of some of the difficulties to be surmounted before more satisfactory methods of preclinical evaluation can be established, may lead to an examination of all commonly used or new anesthetics that will eventually enable the anesthetist to choose accurately an anesthetic that is suitable for the patient and the surgeon, without unduly endangering the life of the former or raising the ire of the latter.

It is suggested that a more valuable preclinical evaluation of anesthetics from the standpoint of respiration could be made if laboratory studies were extended to include, besides their effects on pulmonary ventilation, simultaneous determinations of their effects upon anoxic (chemoreflex control) and hypercapnic (chemoreflex and central control) hyperpnea, upon the hypopnea that is associated with hyperoxia with some anesthetics $^{6}$ (as a means of measuring roughly the func-

\footnotetext{
${ }^{6}$ Evipal (1), pentothal (1), cyclopropane (19).
} 
tional degree of anoxic chemoreflex activity at any depth of anesthesia), upon the Hering-Breuer reflexes under normal and high oxygen tensions (to obtain a rough idea of the changing relationship of vagopulmonary reflexes to the central mechanism), upon sphincteric, ocular, and muscleproprioceptive reflexes (to obtain some evidence as to the effect of the agent upon general reflex excitability), and upon nociceptive excitatory effects on breathing (to determine the masking effect of painful stimuli upon the respiratory signs of depth of anesthesia). A correlation of the data obtained from such experiments seems to afford, as illustrated in this paper, some hope that a successful approach may be found to the problem of the more accurate preclinical evaluation of anesthetic agents.

\section{SUMMARY AND CONCLUSIONS}

The evidence gained from these experiments has been interpreted to indicate that:

The breathing of a normal dog lightly anesthetized with evipal is primarily regulated by carbon dioxide, and that the respiratory exchange necessary to effect the removal of carbon clioxide in some animals at rest is apparently greater than that necessary to maintain an oxygen tension of the arterial blood that will keep the chemoreceptor activities at a level which renders their influence generally undetectable in the intact organism.

An increased depth of evipal or pentothal anesthesia can abolish entirely the center's sensitivity to carbon dioxide, but does not greatly affect the intensity of reflex response to a given hypoxic (chemoreceptive) or physical (vagopulmonary proprioceptive) stimulus. Therefore, under moderately deep evipal or pentothal anesthesia the maintenance of breathing rests in large measure if not entirely upon the peripheral chemoreceptive reflex mechanisms. Respiratory adjustments are made mainly upon the basis of the oxygen need of the carotid and aortic bodies and are not directed toward maintenance of a normal acid-base balance, for a large increase in carbon dioxide tension of the arterial blood is unattended by any change in breathing when the center is sufficiently depressed. However, these same bodies, when subjected to oxygen lack, effect in many instances a greater increase in breathing when the carbon dioxide sensitivity of the center is low than when it is high.

The finding that a high carbon dioxide tension in the arterial blood is incapable of producing increased respiratory activity at a time when a decreased oxygen tension produces a significant stimulation is not construed as evidence that the glomus endings are not being stimulated by carbon dioxide; such an action might well be masked by the clepressant effect of carbon dioxide upon reflexes.

The depression of the respiration of $\log s$ by evipal and pentothal anesthesia shows great individual variation. The number of experiments is too small to permit any definition of the possible limits of variability.

The breathing of oxygen during evipal and pentothal anesthesia, although it delays the onset of anoxemia, does not remove the danger of diminished oxidations. The hypopnea associated with hyperoxia permits the development of hypercarbia. The reduction of oxidations due to the carbon dioxide retention may be more dangerous than the direct anoxia suffered when air is breathed, for as a consequence of this anoxia respiration is stimulated and the accumulation of carbon dioxicle is greatly retarded.

Muscular relaxation with evipal or pentothal of a degree that is readily and safely obtained with ether is prohibited by the danger of respiratory arrest. The use of pentothal or evipal for abdominal or major rectal surgery therefore does not permit the surgeon to work with the facility that is afforded by other agents at a safe level of anesthesia.

The anesthetist is severely handicapped when employing evipal or pentothal because of the variability of response to these agents with the content of the blood gases and other factors discussed. The inability of the anesthetist to determine the status of the respiratory control with the simple means at his disposal seriously handicaps the use of these agents. Generalizations are made as to appropriate factors to study in evaluating new anesthetic agents.

We thank Miss Anne Murphy, B.S., for her excellent technical assistance. 


\section{REFERENCES}

1. Beecher, H. K., and Moyer, C. A., Mechanisms of respiratory failure under barbiturate anesthesia (evipal, pentothal). J. Clin. Invest., 1941, 20, 549.

2. Moyer, C. A., Major changes in the fundamental relationships of the respiratory drive mechanisms during evipal and pentothal anesthesia, with special consideration of possible applications to transpleural surgery. J. Thoracic Surg., 1941, 11, 131.

3. Henderson, Y., Adventures in Respiration. Williams and Wilkins Co., Baltimore, 1938.

4. Marshall, E. K., Jr., and Rosenfeld, M., Depression of respiration by oxygen. J. Pharmacol. and Exper. Therap., 1936, 57, 437.

5. Comroe, J. H., Jr., and Schmidt, C. F., Part played by reflexes from carotid body in chemical regulation of tespiration in dog. Am. J. Physiol., 1938, 121,75 .

6. Haldane, J. S., Respiration. Yale University Press, New Haven, Conn., 1927.

7. Schmidt, C. F., and Comroe, J. H., Jr., Functions of carotid and aortic bodies. Physiol. Rev., 1940, 20, 115.

8. MacLeod's Physiology in Modern Medicine. Edited by Bard, P., C. V. Mosby Co., St. Louis, 1938 and 1941, eds. 8 and 9 . See section on the respiration by C. F. Schmidt.

9. Cordier, D., and Heymans, C., Le Centre Respiratoire. Hermann et Cie., Paris, 1935.
10. Gesell, R., Respiration and its adjustments. Ann. Rev. Physiol., 1939, 1, 185.

11. Gesell, R., A neurophysiological interpretation of the respiratory act. Ergebn. d. Physiol., 1940, 43, 477.

12. Samaan, A., and Stella, G., Response of chemical receptors of carotid sinus to tension of $\mathrm{CO}_{2}$ in arterial blood in cat. J. Physiol., 1935, 85, 309.

13. von Euler, U. S., Liljestrand, G., and Zotterman, Y., Excitation mechanism of chemoreceptors of carotid body. Skandinav. Arch. f. Physiol., 1939, 83, 132.

14. Glazer, W., Regulation of respiration; effects of mechanical asphyxia and administration of carbon dioxide, sodium carbonate, sodium bicarbonate and sodium cyanide on reflex response of anterior tibial muscle of dog. Am. J. Physiol., 1929, 88, 562.

15. King, C. E., Garrey, W. E., and Bryan, W. R., Effect of carbon dioxide, hyperventilation, and anoxemia on knee jerk. Am. J. Physiol., 1932, 102, 305.

16. Gesell, R., and Moyer, C., Is breathing fundamentally a reflex phenomenon? Quart. J. Exper. Physiol., 1935, 25, 13.

17. Beecher, H. K., and Moyer, C. A., Central stimulation of respiration during hypoxia. Am. J. Physiol., 1942, 136, 13.

18. Moyer, C. A., and McKittrick, J. B., Unpublished data.

19. Shackell, L. F., and Blumenthal, R. R., Gaseous anesthetics; the effect of cyclopropane on healthy and tubercular rhesus monkey. Anesth. and Analg., 1934, 13, 133. 